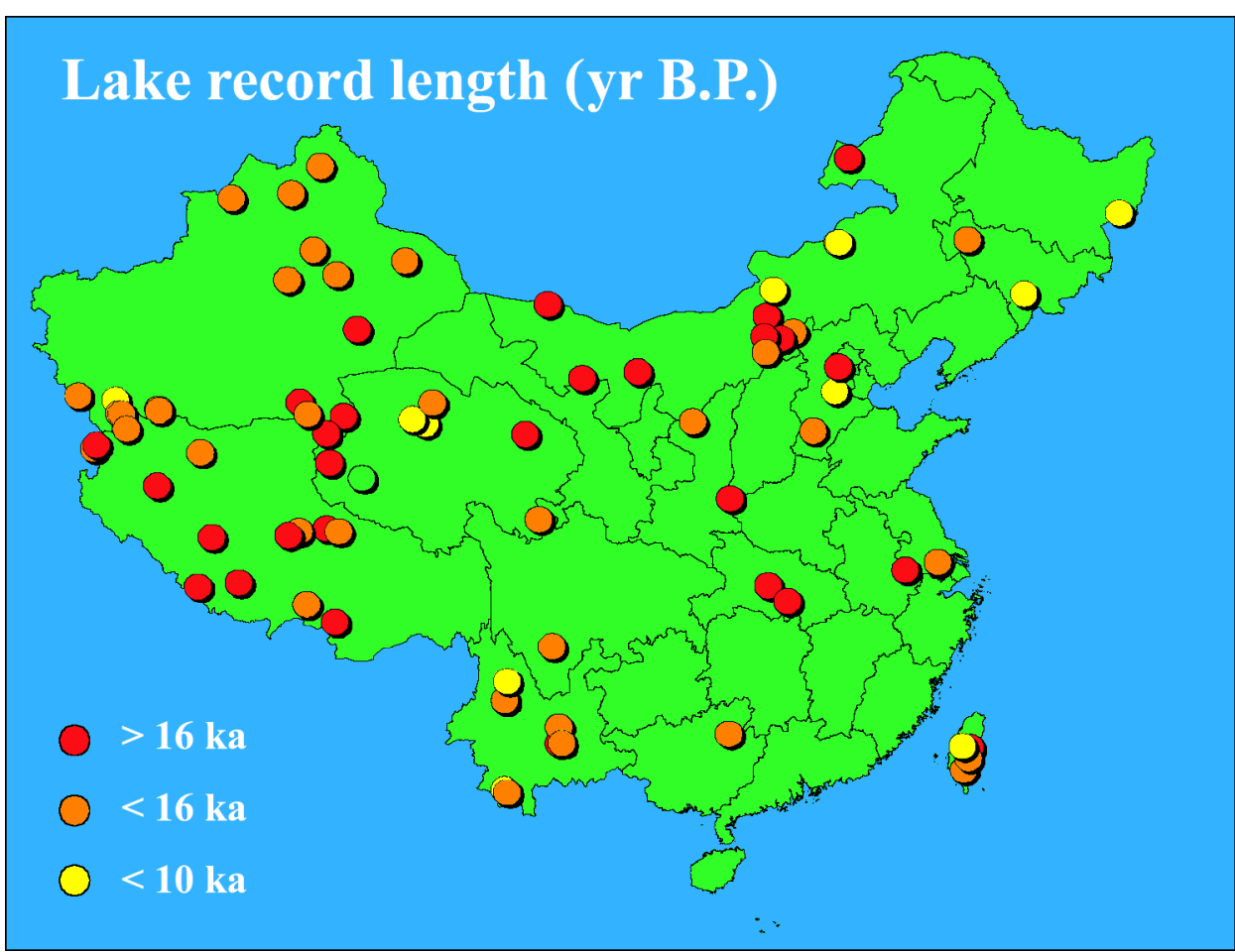

Figure 1: Record length (ka) of lake status from China Lake Status Data Base. Ca 35\% lakes have records spanning beyond the last glacial maximum, and ca 10\% lakes back to 30-40 ka BP.

tional information will also be included for model validation to make the database serve the Earth science community in general. A set of protocols on the CLSDB archiving and accession policy was agreed to during the workshop.

The presentations and discussion raised some key environmental questions:

- What have been the patterns of climate change (precipitation and evaporation) on millennial to century time-scales in Asian monsoon regions?

- What is the relative importance of external forcing (e.g. precessional orbital forcing) vs. internal mechanisms during the period 30-40 ka BP?

- What is the explanation for high lake-level during the LGM in the Tibetan Plateau region?

- What has been the interplay between the westerlies and monsoon systems in eastern and southern Asia?

- What have been the impacts of climate variations during the last millennia on fluvial dynamics in the large river systems of China?

These questions will motivate future data-modeling comparison studies to enhance the understanding of the dynamic mechanisms which underlie cli-

\section{VARVE 99}

\author{
Lammi, Finland, 13-17 ApriL, 1999
}

Interest in annually laminated sediments (i.e. varves) has expanded considerably as studies on short-term and rapid past environmental changes have intensified within global change study programs. The impetus to hold the VARVE 99 workshop originated at the PAGES SSC meeting at Pallanza, Italy in June 1998. The aims of the VARVE 99 workshop, held at Lammi, Jyväskylä and Espoo, and organized by the Geological Survey of Finland (GSF), were to introduce the assembly of field and laboratory methods currently in use in Finland, to give progress reports on ongoing projects, to exchange ideas, and learn of recent advances elsewhere. The participants came from Europe and North America. Several members of the European Lake Drilling Program (ELDP, sponsored by the European Science Foundation) attended the workshop and a meeting of the Northern Europe Regional Group of ELDP was also held. The workshop also stimulated interest within the tree ring community and plans for future co-operation (i.e. in EU funded research programs) were initiated. It is clear that studies of annually laminated sediments will play an increasing role in the PAGES activities.

The workshop was divided into practical field and laboratory sessions, and paper and poster sessions. Lake Korttajärvi in Jyväskylä, Central Finland was visited for a coring demonstration. A coring team from GSF took several long cores using a Kullenberg corer and a piston equipped gravity corer developed at GSF (Figure 1). Working on ice, a three person coring team was able to recover, in less than half an hour, a $10 \mathrm{~m}$ long core from beneath $17 \mathrm{~m}$ of water with the help of $2 \mathrm{~m}$ high tripod and a small engine-operated winch. $300 \mathrm{~kg}$ of lead weights were added to ensure continuous but slow penetration. In principle, water depth is not a limiting factor and up to $15 \mathrm{~m}$ long cores, perhaps longer, can be recovered. Slow penetration seems to produce unbroken sediment sequences, whereas cores taken by a Kullenberg-type gravity corer often contain discontinuities, which are obviously the result of sudden penetration. 
One of the $10 \mathrm{~m}$ long cores from Korttajärvi was opened in the field for demonstration. It was continuously laminated, and probably represents the time since the regional deglaciation at $c$. 10,000 years BP. Korttajärvi is one of the main study sites of GSF, where a complete set of varve study methods has been applied. Five Stone Age dwelling places have been discovered on the shores of the lake and detailed pollen, diatom, charcoal, and mineral magnetic analyses combined with varve counts will reveal the history of past land use. Korttajärvi is a dimictic lake, whose varves are mainly composed of abundant allochthonous minerogenic component from the catchment which is widely covered by fine grained former lake bottom sediments. The sediment accumulation rate has been relatively high and has produced 0.5 to $1.0 \mathrm{~mm}$ thick varves which are easy to identify, scan and digitize (Figure 2).

In Lammi, the classic site of Lovojärvi was visited where much of the early work in the 1970's was undertaken. In situ freezing of the sediment was demonstrated and new varves accumulated during the past two decades were recognized. Diatoms are impor-

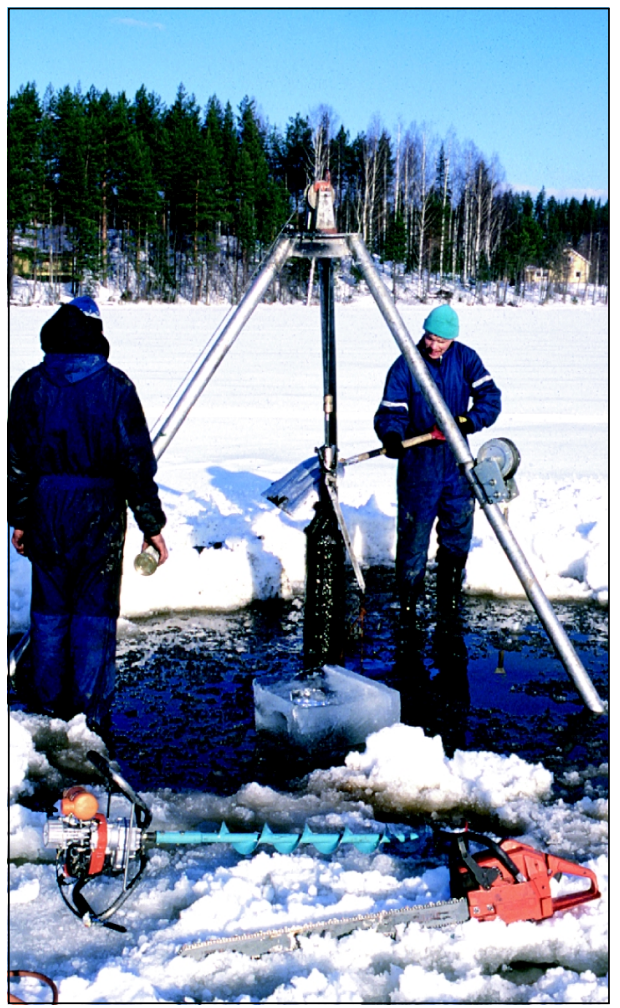

Figure 1: Kullenberg piston corer in operation on lake Pohjajärvi, Finland. The system, designed by the Geological Survey of Finland, can recover a $10 \mathrm{~m}$ long core in a single operation with the aid of just two people. tant components of the varves in Lovojärvi as is the case in many kettle hole lakes in esker environments. In Finland, the annual character of laminated Holocene organic sediments was first recognized in Lovojärvi and Pyhäjärvi in the late 1960's by E. Kukkonen and R. Tynni, geologists at the Geological Survey of Finland. Subsequently, several lakes in the vicinity of the Lammi Biological Station were intensively studied by a number of students. The introduction of the in-situ sediment freezing technique in 1974 was one important step in this first study phase. Emphasis was on the study of the varve characteristics and chronology, especially the land-use history. It was also suggested that variations in varve thickness might prove to be a potential tool in the study of short-term climatic fluctuations.

During the VARVE 99 workshop various techniques were tested in the laboratory in Lammi. These included the digital scanning of $X$-ray radiographs, magnetic susceptibility scanning, color slides and long thin sections. Digitizing of such data for computer handling was also demonstrated. The laboratory facilities of GSF at Espoo were also visited. The current active period in the study of laminated sediments at GSF and Finnish universities has greatly benefitted from improved laboratory techniques and especially from computer based documentation and analysis of laminated sediments. Interpretation of environmental changes as documented by varves is based on advanced interdisciplinary methods such as computerized varve analysis, mineral/paleomagnetism, stable isotope geochemistry, pollen and diatom analysis and microchemical analysis.

By correlating the proxy-climatic data provided by varved lake sediments with tree-ring data representing the same time interval, a more robust interpretation of climatic and environmental changes can be worked out. These topics were discussed at Lammi. Several papers from Arctic Canada emphasized the importance of the link between sedimentary data and meteorological and hydrological data, in order to produce a model linking sediment to climate. This is our ultimate goal, made especially demanding in areas where recent land use has complicated the interpretation of climatic proxies in varved sediments.

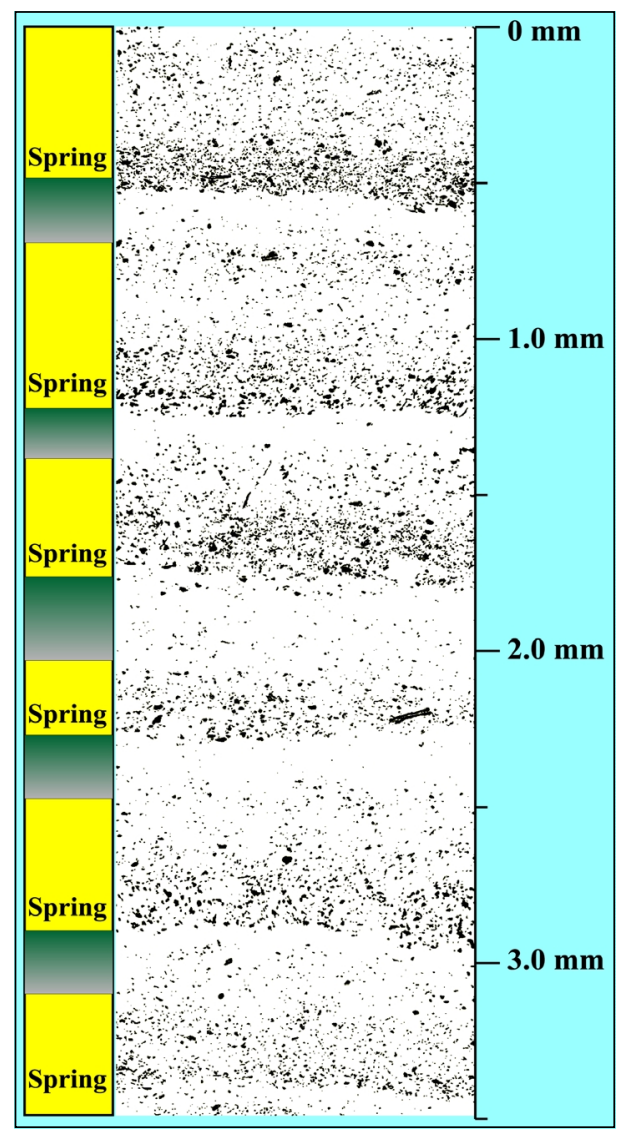

Figure 2: Distribution of mineral grains in a polished thin section (3.5 $\mathrm{mm}$ long) from the sediment of Korttajärvi based on a backscattered electron image.

There is a growing tendency to concentrate on high-resolution analysis of short varve sequences or even to study intra-annual laminae. Despite recent progress, a continuous varved sequence from a site formerly covered by continental ice has yet to be discovered. Such sites probably exist in Finland and would allow time since deglaciation to be counted accurately.

\section{Matti SaArnisto and Timo SaArinen}

Geological Survey of Finland, Espoo, Finland matti.saarnisto@gsf.fi timo.saarinen@gsf.fi

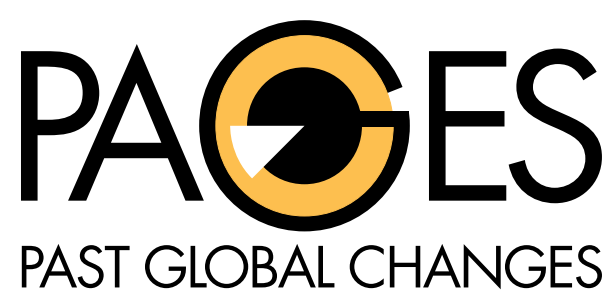

